\title{
MAGISTÉRIO INDÍGENA GUARANI MBYA NO RIO DE JANEIRO: UMA PERSPECTIVA DECOLONIAL DE EDUCAÇÃO DIFERENCIADA
}

\author{
Domigos Barros Nobre ${ }^{\mathrm{i}}$ \\ Anna Beatriz Albuquerque Vecchia ${ }^{\text {ii }}$
}

\begin{abstract}
Resumo: O artigo visa apresentar reflexões teóricas acerca do processo de implantação do primeiro Curso de Ensino Médio com Habilitação em Magistério Indígena Guarani do Estado do Rio de Janeiro, iniciado em 2018. O Curso é resultado de um Acordo de Cooperação Técnica entre o IEAR - Instituto de Educação de Angra dos Reis da UFF - Universidade Federal Fluminense e a SEEDUC-RJ - Secretaria de Estado da Educação do Rio de Janeiro. A discussão busca refletir sobre os elementos ou componentes curriculares do referido Curso que apontam para a preservação e fortalecimento da cultura e língua indígena, numa perspectiva decolonial de educação diferenciada além de analisar criticamente o contexto de crise e retrocesso nas políticas públicas em educação escolar indígena no Estado do Rio de Janeiro.
\end{abstract}

Palavras-chave: Educação Escolar Indígena; Magistério Indígena; Educação Diferenciada.

\section{LINCENSED HIGH SCHOOL INDIGENOUS MBYA GUARANI TEACHING DEGREE RIO DE JANEIRO STATE: A DECOLONIAL PERSPECTIVE ON DIFFERENTIAL EDUCATION}

\begin{abstract}
The article is intended to bring forward theoretical thinking on the process of establishing the first Lincensed High School Guarani Indigenous Teaching Course of Rio de Janeiro State, established in 2018. This Course is a result of a Technical Cooperation Agreement between IEAR- Educational Institute Angra dos Reis - Federal Fluminense University (UFF) and SEEDUC-RJ- Rio de Janeiro Educational Department. This debate aims to consider curricular elements or contents of the Course intended to preserve and strengthen indigenous culture and language, from a "decolonial" perspective of differential education in addition to taking a critical look in the context of crisis and setbacks of public policies on indigenous education in Rio de Janeiro State.
\end{abstract}

Keywords : Academic Indigenous Education; Indigenous School Teaching Degree;

Differentiated Education.

Este texto visa apresentar as primeiras reflexões teóricas acerca do processo de implantação do Curso de Ensino Médio com Habilitação em Magistério Indígena Guarani no Estado do Rio de Janeiro, no Colégio Indígena Estadual Guarani Karai Kuery Renda em 


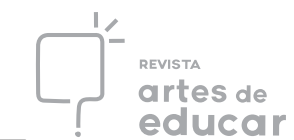

2018. Está organizado em três partes: na primeira, "Contexto Histórico", busca apresentar as condicionantes socio-históricas que cercaram o processo de implantação de uma política pública cuja demanda histórica estava reprimida desde 2000, como a legislação atrasada, os direitos ainda não atendidos e finalmente a judicialização, através da intervenção do MPF Ministério Público Federal. Na segunda, "Perspectiva Decolonial do Curso", intenta elencar elementos da proposta de implantação que potencializam uma pespectiva sócio-histórica de decolonialidade, na escolarização e formação de professores indígenas. Tais elementos como a presença ativa do bilinguismo; a participação de professores indígenas no processo; o tripé Ensino, Pesquisa e Extensão organicamente integrados na participação da Universidade, assim como componentes curriculares intrinsicamente ligados aos saberes tradicionais indígenas como a Disciplina: Cosmologia Indígena, assim como a parceria e apoio dos movimentos sociais locais, são aqui apontados como potenciais elementos que contribuem para o fortalecimento da identidade étnica Guarani, de sua cultura e de sua língua materna. Finalmente, a terceira parte: "Concepção da Disciplina: Prática Reflexiva" objetiva apresentar a estrutura e os fundamentos teórico-metodológicos da disciplina que o IEAR/UFF coordena e ministra no referido curso. Tal componente curricular vem acompanhado da disciplina: "Pesquisa" que organicamente a integra, possibilitando experiências formativas sob um viés da pedagogia progressista de inspiração freireana e sócio-histórica.

\section{Contexto Histórico:}

A luta dos Guarani Mbya no Rio de Janeiro por educação escolar indígena diferenciada não é recente. Ainda hoje os indígenas sofrem com o abandono de políticas públicas educacionais por parte do Estado. A educação indígena, em Angra dos Reis e Parati, é ofertada pelo Colégio Indígena Estadual Guarani Karai Kuery Renda - CIEGKKR, e para falarmos sobre a implantação do Curso de Ensino Médio com Magistério Indígena, cabe um breve levantamento histórico da luta dos Guarani por uma educação escolar indígena na Aldeia Sapukai e uma análise crítica da situação de crise e atraso histórico que ainda permanecemos.

Os Guarani chegaram em Angra dos Reis em 1982, com o Cacique Verá Mirim e sua família. Em 1994, após o processo de auto-demarcação da aldeia junto à FUNAI, construíram 
a "Escola Indígena Guarani Kyrĩgue Yvotyty"iii", na época comunitária, e que mais tarde se tornaria Colégio Indígena Estadual Guarani Karai Kuery Renda ${ }^{i v}$.

O período histórico em que a escola foi comunitária possibilitou a construção de um PPP- Projeto Político Pedagógico junto com a comunidade indígena, em oficinas de formação continuada, das quais participaram os professores da escola, lideranças indígenas, ramoi e jaryi $^{v}$, parteiras e jovens. Foram realizados Encontros Interestaduais, Regionais e um Encontro Nacional de Educadores Indígenas Guarani na Escola Indígena da Aldeia Sapukai nesse período, o que mantinha viva e atualizada a reflexão coletiva entre os professores guarani e que alimentava a construção de um currículo integrado.

Em 1999, foi criado o NEI-RJ - Núcleo de Educação Indígena do Estado do Rio de Janeiro, que era um fórum interinstitucional estadual de diferentes agentes que atuavam na área de educação escolar indígena no Estado do Rio de Janeirovi ${ }^{\mathrm{vi}}$ e tinha como objetivos:

\begin{abstract}
Potencializar as ações de assessoria em educação escolar indígena; Promover ações cooperativas e coordenadas com mesmos objetivos; Evitar superposição e/ou fragmentação de ações na área; Discutir processo de legitimação e legalização dos Projetos Educativos Guarani no Estado, Processos de reconhecimento e autorização para funcionamento junto ao CEE-RJ - Conselho Estadual de Educação; Programa de Formação de Educadores/as Indígenas; Programa de Construção Curricular; Elaborar projetos para captação de recursos" (NEI-RJ, 1999).
\end{abstract}

O NEI-RJ teve duração de apenas 3 anos (1999 a 2001) e só muito mais tarde, em 2017, é que foi criado o atual CEEEI-RJ - Conselho Estadual de Educação Escolar Indígena no Rio de Janeiro, dentro da estrutura administrativa da SEEEDUC-RJ, que ainda se encontra em fase de implementação devido aos trâmites jurídicos da SEEDUC-RJ. Isso demonstra inequivocamente o atraso histórico do Rio de Janeiro, no tocante à uma articulação interinstitucional das políticas públicas para o setor.

Em 2003, com o Decreto Estadual N. ${ }^{\circ}$ 33.033, foi criada a categoria "Educação Escolar Indígena" nos sistemas estadual e municipal de ensino, no âmbito da educação básica. Nele, define-se que: A Escola Indígena será criada em atendimento à reivindicação, por iniciativa ou com a anuência de comunidade interessada, respeitadas suas formas de 


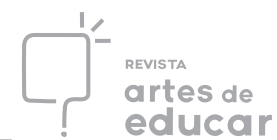

representação (Rio de Janeiro, 2003). Em seguida, no mesmo ano, a SEEDUC-RJ implantou o Ensino Fundamental I nas aldeias Guarani do Estado.

Em 2004, a Deliberação CEE n 286, estabeleceu normas para autorização, estrutura e funcionamento das escolas indígenas no âmbito da educação básica no sistema de ensino estadual do Rio de Janeiro. O Poder Executivo estadual obrigar-se-á a proporcionar a habilitação de nível Médio na modalidade Normal e no nível Superior, de recursos para o magistério das Escolas Indígenas, utilizando para tal, processos seletivos específicos. Em seguida, em 2005, com o Decreto Estadual No 38.125, foi criada a Escola Indígena Estadual Karai Kuery Renda.

Entre 2003 e 2010, foram abertas duas turmas de EJA Guarani - Educação de Jovens e Adultos Guarani, para atender às demandas de escolarização no Ensino fundamental para agentes indígenas de saúde e de saneamento, contratados pela então chamada Fundação Nacional de Saúde (FUNASA). O projeto organizado pela Secretaria Municipal de Educação de Angra dos Reis, em parceria com a FUNASA, Universidades (UFF, UERJ, UNIRIO e UFRJ), FUNAI e Fundação Rondonistas de Santa Catarina, atendeu indígenas das comunidades de Angra dos Reis (Sapukai) e Paraty (Itaxim, Araponga, Mamanguá e Rio Pequeno), formando duas turmas, num total de 35 alunos.

Posteriormente, seis professores indígenas cursaram o Magistério Indígena, no projeto intitulado: "Protocolo Guarani" que iniciou em 2003, finalizando em 2011 e conferindo a eles certificação de nível médio em magistério.

Em 2014, ocorreu a formatura da terceira e última turma da EJA Guarani - a Secretaria Municipal de Educação de Angra dos Reis ministrou o $2^{\circ}$ segmento na modalidade presencial e intercultural, realizado na Escola Municipal Professor Francisco de Oliveira Diniz, no Sertão do Bracui, com assessoria pedagógica do IEAR/UFF.

A implantação dessas três turmas de EJA Guarani, ao longo desses onze anos (2003 a 2014) através de projetos educacionais inicialmente criados para atender uma exigência da legislação federal que determinava a obrigatoriedade de conclusão do primeiro segmento do fundamental para agentes comunitários indígenas de saúde e de saneamento, demonstra o descaso histórico que o Estado do Rio de Janeiro mantém com as comunidades indígenas no Rio de Janeiro. A legislação federal que regulamenta a oferta de educação escolar indígena data do final dos anos 1990, a saber: as DCNEEI - Diretrizes Curriculares Nacionais para as 
Escolas Indígenas - CNE de 1999 e os RCNEInd - Referenciais Curriculares Nacionais para as Escolas Indígenas de 1998.

Em seguida, em 2015, a SEEDUC-RJ implantou o Ensino Fundamental II nas aldeias, com professores juruá vii , onde o IEAR/UFF faz a formação continuada, pois, devido à ausência de professores indígenas habilitados em cursos de licenciatura no estado do Rio de Janeiro, os professores que dão aula nas escolas não são indígenas e alguns nunca tiveram contato com a cultura Guarani antes de darem aula nas aldeias.

Em 2018, a SEEDUC-RJ implantou o Curso de Ensino Médio com Habilitação em Magistério Indígena, entretanto, para falarmos dele, precisamos voltar em 2012 quando a SEEDUC- RJ abriu o processo para a instauração do Curso de acordo com a deliberação do CEEI- RJ e então foi iniciada a luta pela sua implantação. Para o Magistério Indígena poder ser um curso regular da Escola Indígena Estadual Guarani Karai Kuery Renda, foi preciso transformá-la em Colégio, de acordo com a Resolução SEEDUC No 5227 que:

Transforma em Colégio Indígena Estadual a Escola Indígena Estadual Guarani Karai Kuery Renda, criada pelo Decreto $n^{\circ} 38.125$, de 15 de agosto de 2005, publicado no Diário Oficial de 16 de agosto de 2005, localizada na Aldeia Sapukai, em Bracuí, Angra dos Reis. (RIO DE JANEIRO, 2015)

É importante lembrar que essa demanda por escolarização nas aldeias Guarani do Rio de Janeiro dura há mais de 10 anos. Uma ACP - Ação Civil Pública impetrada pelo MPF que resultou numa sentença judicial, após anos de trâmites jurídicos por parte do estado, determinou que o Curso fosse implementado. Finalmente, em julho de 2018 as aulas no Magistério Indígena começaram.

\section{Implantação do Curso}

O Curso de Ensino Médio com Magistério Indígena é uma parceria entre o IEAR/UFF e a SEEDUC- RJ, através um Acordo de Cooperação Técnica, ou seja, a UFF dá assessoria e faz a coordenação pedagógica do curso; nele lecionam professores juruá que dão aula nas disciplinas obrigatórias do Ensino Médio, da BNCC - Base Nacional Comum Curricular; e 
professores indígenas dando aula nas disciplinas da Parte Diversificada, específicas da cultura Guarani Mbya, como a disciplina de Língua Guarani.

Durante o primeiro semestre, o curso funcionou em regime de alternância, dividido em "tempo escola" e "tempo comunidade". Dessa forma, no tempo escola, os alunos assistiam aula na escola durante três semanas e depois retornavam para a comunidade para o tempo comunidade. Isso foi possível graças a participação de bolsistas de extensão PROEXT ${ }^{\text {viii }}$, do Programa de Extensão: "Escolarização e Cultura Guarani Mbya Rumo à Universidade"; de bolsistas de ensino do Programa Licenciatura: "Formação de Professores na Educação Escolar Indígena Guarani Mbya" e uma bolsista de iniciação científica do Projeto PIBIC ${ }^{\mathrm{ix}}$ : “A Construção de Currículos Diferenciados Indígenas, Caiçaras e Quilombolas na Costa Verde", que são alunos dos cursos de licenciatura em Pedagogia e Geografia, e do bacharelado em Políticas Públicas, do IEAR-UFF.

Os alunos indígenas foram acompanhados pelos bolsistas todos os dias, principalmente nos tempos comunidade, onde realizavam atividades orientadas pelos professores regentes. Três tempos comunidade foram destinados à parte Formação Profissional, do currículo, onde foram trabalhadas as disciplinas da área pedagógica "Prática Reflexiva" e "Pesquisa", possibilitando a realização de oficinas em que os alunos indígenas elaboraram um Diagnóstico Sociocultural e um Diagnóstico Sociolinguístico da comunidade, como etapa integrante da metodologia de construção curricular adotada.

Além disso, também foi realizada uma Oficina de Audiovisual, como parte da disciplina: "Linguagens Audiovisuais", onde os alunos produziram quatro curtas-metragens, como resultado deste Diagnóstico Sociocultural e também foi realizada uma Oficia Básica de Fotografia, na qual os alunos produziram fotos para alimentar uma outra atividade realizada, a Oficina de Cartografia Social. Estas oficinas serão mais detalhadas nos tópicos seguintes deste trabalho, pois, entendemos que são importantes práticas decoloniais presentes no currículo do Curso de Magistério.

A maioria dos alunos do Curso de Magistério Indígena, vieram da última turma da EJA Guarani e quatro deles são professores e alfabetizadores do Ensino Fundamental I, na aldeia.

\section{Perspectiva decolonial do Curso:}


Vamos aqui neste tópico, elencar sete dimensões do processo em curso que consideramos relevante pra construção de uma proposta educativa intercultural crítica e decolonial, a saber: a metodologia adotada para a reorientação curricular proposta pelo Curso; o grau e a qualidade do bilinguismo presente no Curso; a presença de elementos/componentes curriculares ligados aos saberes tradicionais indígenas e aos seus agentes indígenas produtores, incorporando perspectivas teóricas indígenas junto às ciências e saberes acadêmicos não indígenas no currículo; o espaço de reflexão crítica que mobiliza os alunos pra suas pautas de reinvidicação políticas, como: teritório, saúde e educação; a participação ativa e autônoma de alunos da Universidade no desenvolvimento do Curso; a integração orgânica entre Ensino, Pesquisa e Extensão na participação da Universidade e finalmente, a parceria e apoio dos movimentos sociais através do FCT - Fórum de Comunidades Tradicionais de Angra dos Reis, Parati e Ubatuba, com seu Coletivo de Apoio à Educação Diferenciada de Parati.

\section{A metodologia de construção curricular adotada}

O primeiro módulo do Curso começou com a disciplina: "Prática Reflexiva" ministrada pelo IEAR/UFF e teve o objetivo de introduzir os fundamentos de uma metodologia de construção de currículos diferenciados em escolas de comunidades tradicionais. Tal metodologia vem sendo desenvolvida pela UFF de Angra dos Reis em comunidades indígenas, caiçaras e quilombolas desde 2015, dentro do Programa: "Escolas do Território $^{x}$ " através de parcerias com a SEEDUC-RJ, que mantém o Colégio Indígena Estadual Guarani Karai Kuery Renda - CIEGKKR; e com a SME - Secretaria Municipal de Educação de Paraty, que mantém as escolas de primeiro segmento na região Costeira, de segundo segmento nas Praias do Sono e Pouso da Cajaíba e nas escolas de primeiro segmento dos Quilombos do Campinho e do Cabral.

O Programa Escolas do Território vem se desenvolvendo com uma consistente base conceitual e metodológica para a reorientação curricular desenvolvida por Nobre (2018), baseada em referências na pedagogia de projetos (Hernández, 1998; Hernández; Ventura, 1998), aprendizagem significativa de Ausubel (Moreira, 2006), interculturalidade crítica 


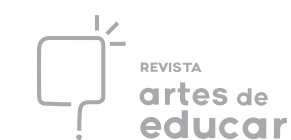

(Tubino, 2011; Walsh, 2007; Candau; Russo, 2010) e temas geradores (Freire, 1970). O desafio a que o referido programa se propõe, segundo Monteiro (2018), se dá basicamente em duas frentes de investigação e prática: uma articulação entre currículo, saberes e território e uma abordagem inovadora de mediação entre conceitos integradores e conteúdos programáticos no Ensino Fundamental.

A metodologia adotada baseia-se nos temas geradores organizados numa rede temática, de base freireana e na pedagogia de projetos e toma os conceitos integradores de cada área de conhecimento como essencial nos critérios de seleção e ordenação sequencial dos conteúdos na organização do currículo integrado e interdisciplinar. A proposta da disciplina é que os alunos (quatro deles já são professores no Colégio Indígena) experimentem no curso a mesma metodologia que se propõe para o Colégio indígena no primeiro e segundo segmento.

\section{O bilinguismo presente}

Adotando sugestões de Knapp (2016), que baseado em Martins \& Knapp (2015), faz uma descrição das principais políticas linguísticas que visam a valorização, a manutenção e a ampliação de uso das línguas indígenas nos cursos de licenciatura indígena (ou de magistério indígena de nível médio), podemos avaliar as práticas pedagógicas neste curso de formação, a partir de algumas categorias de análise, quanto às práticas pedagógicas, tais como:

a) Registro das memórias das aulas em língua indígena e em língua portuguesa; Há um caderno de campo onde cada aluno, em cada dia de aula, faz um relato síntese das atividades desenvolvidas pela turma naquele dia;

b) Espaço garantido nas aulas para tradução em língua indígena das explicações dadas em língua portuguesa. É obrigatório a escolha de um "Tradutor" entre os alunos a cada dia de aula, para fazer a traduçnao para o Guarani, das explicações dadas pelos professores juruá;

c) Realização de pequenas cerimônias na escola em língua indígena. Pequenas apresentações de Xondaro e Tangará já são feitas no espaço escolar;

6- Presença de professores bilíngues no Curso/Escola. Há várias disciplinas do currículo que são e serão ainda ministradas por Guarani bilingues; 
7- Professores não-indígenas estudando a língua indígena. Foi montado um GT de Língua Guarani em que participam 3 professores não indígenas, sob assessorial de linguistas do Museu Nacional - UFRJ;

9- Práticas de oralidade e escrita em ambas as línguas e reflexões linguísticas em ambas as línguas. Algumas disciplinas já garantem esse espaço.

12- Elaboração de materiais e recursos didáticos em língua indígena ou bilingues. Já foram produzidos 3 curtas-metragens em Língua Guarani e Português, na I Oficina de Audiovisual. Está sendo elaborado dois livros de Ensino de Língua Guarani pra Ensino Médio e Fundamental II, com assessoria de linguistas do Museu Nacional UFRJ pelo GT de Lingua Guarani.

A presença de saberes tradicionais indígenas como elementos/componentes curriculares que incorporam perspectivas teóricas indígenas junto às ciências e saberes acadêmicos não indígenas no currículo

No currículo do Curso estão incluídas componentes curriculares que serão desenvolvidos por lideranças intelectuais guarani, ramôi e jaryi nas seguintes áreas:

1) Lingua Guarani e Linguística Aplicada, com Algemiro da Silva Karai Mirim (RJ).

2) Cosmologia Guarani, com Algemiro da Silva Karai Mirim e Timóteo Popygua (SC).

3) Organização Social Guarani, com Lucas Xunu Mirim (RJ).

4) Direitos, Lutas e Movimentos Indigenas, com Luiz Karai (SP), Gizelda Ara Jera (SP) e Toninho Kuaray (ES).

5) Linguagens Audiovisuais, com Claudio Karai Papa, Isaias Vera Mirim, Alberto Alvares, Thiago Vera Mirim e Francisco Piriria.

6) Nhandereko, sendo:

- Religião, com Adolfo Timóteo (SP) e Cacique Agostinho (RJ)

- Cultura, com Cacique Felix e Adolfo Timóteo (SP)

- Saúde, com a parteira Genira e o Agente de Saúde Pedro (RJ)

- Educação, com Adolfo Timóteo (SP) e Timóteo Popygua (SC)

\section{O espaço de reflexão crítica que mobiliza os alunos indígenas}


Um efeito prático das reflexões promovidas no Diagnóstico Sócio-cultural da Aldeia Sapukai, no âmbito da disciplina: "Práticas Reflexivas", foi um maior envolvimento do jovens e adultos alunos indígenas nas discussões que envolvem os problemas de suas comunidades, em especial, educação e saúde.

Viu-se, ao longo do semestre, uma maior união entre os alunos com um reforço do grau de pertencimento ao Curso e um grande interesse no debate de suas demandas. Como exemplo, alguns se envolveram diretamente na mobilização que os indígenas do sul-sudeste promoveram frente à ameaça de desmonte do atendimento de saúde na DSAI ${ }^{\mathrm{xi}}$ - Distritos Sanitários Especiais Indígenas, sediado em Curitiba. Assim como debateram intensamente a crise educacioanl pela qual o Rio de Janeiro atravessa e o papel da comunidade indígena na defesa de seus direitos.

\section{A participação ativa e autônoma de alunos da Universidade}

O IEAR/UFF manteve em 2018 uma equipe de 11 bolsistas acompanhando regularmente o Curso. Bolsistas de Extensão, de Ensino e de Pesquisa de projetos já citados anteriormente, envolveram-se em reuniões de planejamento, nas Oficinas de Linguagens Audiovisuais (de vídeo e de fotografia), de Cartografia Social e principalmente nas aulas do "Tempo Comunidade", onde ministraram as atividades planejadas e orientadas pelos professores regentes, sob a Supervisão do Coordenador do Curso. A proposta de iniciação à docência, prevista pelo Curso, envolve a dimensão da formação de professores indígenas e não indígenas para atuar em Educação Escolar Indígena, na construção de currículos diferenciados, bilingues e interculturais. A atuação dos bolsistas em atividades de formação continuada de acompanhamento ao Curso envolvem uma dimensão fundamental da docência que é o processo de formação de professores voltado para a autonomia na construção de currículos integrados e interdisciplinares.

Tal envolvimento, traz importantes contribuições teórico-metodológicas à formação dos estudantes de licenciatura (e bacharelado), no sentido de que utiliza uma metodologia qualitativa de formação continuada voltada para a construção de currículos diferenciados integrados, bilingues e interculturais, baseada nos temas geradores (numa perspectiva 
freireana) em redes temáticas e na pedagogia de projetos, assim como adota um método de análise didática a partir de aulas filmadas baseado num roteiro pedagógico de análise didática de aulas.

Para tal, são filmadas as aulas, editadas na Ilha de Edição do IEAR e analisadas no Grupo de Estudos e Pesquisa ${ }^{x i i}$.

Para a filmagem, utiliza-se uma técnica de seleção de imagens que busca acompanhar "ao vivo" a natureza das atividades e o tempo de cada uma, que o professor realiza em sala, decupando o conjunto da aula, em momentos, passos, etapas nos quais ela se constitui. Avalia-se se o que se está registrando expressa o mais fiel possível, aquele momento da aula escolhido.

Para a edição, utiliza-se uma técnica de cortes que busca acompanhar essa decupagem inicial, de forma que preserve-se um pouco de registro para cada momento da aula. O objetivo é que com apenas alguns minutos de filmagem de cada momento/etapa da aula, eles expressem como foi o conjunto da aula, permitindo que esses momentos sejam identificáveis na análise. Uma aula de 3 horas de duração fica com no máximo 15 minutos, depois de editada.

Para a análise das aulas, utiliza-se um Roteiro de Análise Didática, composto de:

1- Passos da aula: onde recupera-se as etapas que encadeiam o conjunto de atividades e elementos, que integra a aula;

2- Objetivos da aula: onde recuperam-se os objetivos postos pelo professor para aquela aula;

3- Aspectos positivos: onde elencam-se os elementos componentes da aula que cumpriram forte papel no atendimento aos objetivos previstos pelo professor;

4- Questões teóricas: onde se produz questões de natureza metodológica ou conceitual/de conteúdo levantadas a partir da prática pedagógica expressa naquela aula.[L-

Tal roteiro de análise didática, tem-se demonstrado fértil ao contribuir pra exercitar a reflexão teórica sobre as práticas pedagógicas de professores em formação continuada, na medida em que possibilita, entre outras coisas:

a. Ter uma visão da aula em seus momentos/etapas componentes (Passos da Aula); 
b. Priorizar como instrumento de análise os objetivos da aula;

c. Valorizar os elementos positivos do acervo de práticas pedagógicas do professor;

d. Estimular o exercício de reflexão teórica da prática pedagógica a partir da própria prática;

e. Reconhecer a aula como um fenômeno complexo e multifacetado, que expressa uma concepção de currículo em construção;

f. Valorizar o os saberes docentes, na medida em que o grupo toma a aula como instrumento/material de estudo;

g. Experimentar uma prática de construção curricular que toma o desafio da reorientação curricular como tarefa coletiva.

Essa etnografia da aula, está organicamente ligada ao processo de construção de uma proposta curricular diferenciada, bilingue e intercultural, que perpassa o Curso, tornando-se seu objetivo principal.

As atividades desenvolvidas pelos bolsistas trará à Universidade, uma efetiva contribuição, para além da formação docente, pois está em curso, a construção de uma política pública ancorada nos movimentos sociais, pois no caso, o Curso conta com o apoio do FCT - Fórum de Comunidades Tradicionais de Angra dos Reis, Parati e Ubatuba e do Coletivo de Apoio à Educação Diferenciada de Parati (abaixo descrito no ítem 2.7), além do exercício de uma metodologia de construção curricular para escolas em comunidades tradicionais (Indígenas, Caiçaras e Quilombolas).

Estes são os únicos espaços práticos de formação acadêmica regular em Educação Escolar Indígena atualmente funcionando no Rio de Janeiro e representam uma importante política pública educacional nessa área.

\section{A integração orgânica entre Ensino, Pesquisa e Extensão}

O ciclo docente que envolve a formação contínua, a construção curricular e a produção de material didático, que o Curso vem possibilitando, envolvendo os graduandos da Universidade, se apoia no tripé: Ensino, Pesquisa e Extensão e vice-versa. 
A Pesquisa busca qualificar a construção curricular quando cria uma categoria de análise para se pensar a prática pedagógica dos professores no Curso: componentes curriculares que potencializem o papel da escola na preservação/fortalecimento da língua e da cultura guarani.

O Ensino busca tomar a aula dos professores como objeto de estudo e reflexão teórica ao analisá-las didaticamente.

A Extensão busca sustentar as tarefas de registro das aulas pra análise didática assim como, organizar aulas planejadas pelos professores regentes e acompanhadas pela Coordenação e também subsidiar o processo de produção de material didático, que se dá, também numa perspectiva de formação.

Parceria com os movimentos sociais através do FCT - "Fórum de Comunidades Tradicionais de Angra dos Reis, Parati e Ubatuba" e de seu "Coletivo de Apoio à Educação Diferenciada"

O Programa: "Escolas do Território", ao qual o Curso de Magistério Indígena integra tem o apoio do FCT e do Coletivo - duas organizações populares que atuam há muitos anos na região na luta pela defesa do território das comunidades tradicionais e suas demandas sociais:

O Fórum de Comunidades Tradicionais - FCT é um movimento social de base comunitária que surgiu a partir da união de indígenas, quilombolas e caiçaras da região da Bocaina - Angra dos Reis, Paraty e Ubatuba, em busca de fortalecimento e solução para problemas comuns relacionados a direitos básicos e principalmente, para assegurar o direito ao território. O FCT foi criado em 2007, a partir do surgimento de políticas importantes para os Povos e Comunidades Tradicionais do Brasil, como o Decreto 6040/2007 que institui a Política Nacional de Povos e Comunidades Tradicionais e tem como principal objetivo: promover o desenvolvimento sustentável dos Povos e Comunidades Tradicionais, com ênfase no reconhecimento, fortalecimento e garantia dos seus direitos territoriais, sociais, ambientais, econômicos e culturais, com respeito e valorização à sua identidade, suas formas de organização e suas instituições (Coletivo de Apoio à Educação Diferenciada, 2018, p. 4). 
Essa parceria, garante que a direção política dada às ações oriundas de acordos de cooperação técnicos assinados entre a Universidade e o poder público atenda aos interesses reais dessas comunidades e que sejam discutidas coletivamente. Isso mantém a reflexão política atualizada, horizontalizada e coletiva, o que faz com que o trabalho de formação pedagógica coordenado pela Universidade esteja ancorado nos princípios de uma educação bilingue, intercultural e diferenciada que fortaleça a identidade étnica e cultural dos Guarani e sua língua materna, defendida pelo FCT e pelo Coletivo:

O FCT se articula em rede de associações comunitárias e entidades parceiras, buscando o fortalecimento das comunidades tradicionais. Exerce o controle social, pressão participativa e luta pela democracia, atuando em espaços colegiados como conselhos, redes e fóruns regionais. Promove defesa dos direitos essenciais e territoriais das populações tradicionais por meio de articulação, mobilização e diálogo com instituições governamentais e não governamentais que atuam na defesa desses povos, como Ministério Público, Defensoria Pública, universidades, centros de pesquisa e ONGs. O FCT exerce ainda atuação importante como criador e indutor de políticas públicas a representantes do poder legislativo.

Há também representantes indígenas no CEEEI-RJ - Conselho Estadual de Educação Escolar Indígena do Rio de Janeiro (com 50 \% de representatividade), instalado em 2018 e cujo presidente indígena é o professor Algemiro da Silva Karai Mirim, também professor do Curso de Magistério Indígena e indígenas também atuando no FCT, como Júlio Garcia e Adilson Tupã, além de jovens indígenas no Grupo de Jovens do Coletivo.

\section{Concepção da Disciplina: "Prática Reflexiva"}

A disciplina foi concebida para dar subsídios à reelaboração e atualização do PPP do Colégio Indígena Karai Kuery Renda além de servir de instrumental pedagógico para formação em Didática e Prática de Ensino, dos futuros professores indígenas. Em sua ementa consta que:

A prática pedagógica exige um contínuo exercício de reflexão sobre a ação e de reflexão na ação. Tal processo demanda um planejamento sistemático de diversas atividades orientadas que permitam tal exercício de reflexão. 
Consiste em períodos de aula presenciais aliados a períodos de trabalho de campo orientados por monitores bolsistas" (NOBRE, 2017).

Consta como competências específicas a serem desenvolvidas, entre outras:

Propiciar aos professores a reflexão teórica sobre sua prática pedagógica; Promover a análise crítica de diferentes materiais didáticos, assim como experimentar processos de elaboração e produção de seus próprios materiais; Promover a troca de experiência entre os professores; Refletir sobre as diferenças entre as formas tradicionais de produção e transmissão de conhecimentos culturalmente construídas pelo povo Guarani e as formas escolares da sociedade não-indígena; Subsidiar o processo de construção de Currículos e Calendários escolares diferenciados e específicos para as suas escolas, assim como para a organização da documentação escolar (NOBRE, 2017).

Entendemos que essa concepção, da forma como foi elaborada e vem sendo realizada até agora, pode possibilitar um percurso formativo diversificado e plural que permita habilitar aos indígenas um exercício da função crítico e autônomo, na medida em que ela vem acompanhada da disciplina: "Pesquisa", cuja ementa abrange, entre outros domínios:

Os processos, instrumentos e práticas envolvidos na construção do conhecimento em seu sentido amplo, com ênfase nos processos de reflexão e sistematização de experiências no campo educativo. Seu caráter consolidador dos aspectos prática-teoria-prática num contexto epistemológico exigem um trabalho de produção e reflexão permanente do aluno que se realizará em atividades práticas dirigidas em aula e em pesquisas individuais e coletivas (NOBRE, 2017).

O componente "Pesquisa", desenvolvido a par e passo com "Prática Reflexiva" supõe, segundo o PPP do Curso, o desenvolvimento de algumas competências gerais, tais como:

Resgate, registro e documentação da própria cultura, bem como sua interface com a sociedade não indígena; Compreender o valor do conhecimento sistematizado para tomada de decisões, na atuação pedagógica e nas interferências decorrentes da relação com a sociedade nacional; Permitir o desenvolvimento de competências de pesquisa relacionadas a diferentes possibilidades que se apresentam ao campo da pesquisa em educação, tais como: o uso de imagens e outras fontes que permitam o mergulho no estudo das redes de saberes que tecem o campo epistemológico do cotidiano; 
Estratégia de construção de práticas interculturais de construção de conhecimentos e autoria de materiais didáticos específicos. (Idem)

Neste sentido, seu desenvolvimento fez uso de estratégias metodológicas constantes da metodologia de construção curricular adotada pelo IEAR/UFF na formação continuada de professores caiçaras, quilombolas e indígenas do Programa: "Escolas do Território".

A formação continuada nesse Programa é estruturada em torno de 3 eixos, que serão também perseguidos no Curso:

A) O estudo e construção de uma nova "Visão de Área" coerente com os princípios político-pedagógicos de tendências pedagógicas progressistas, contendo estudos que contemplam: a) Epistemologia da disciplina; b) Tendências pedagógicas no ensino da disciplina e c) Conceitos integradores de cada Área do Conhecimento.

B) Análise didática das práticas pedagógicas (a partir das filmagens da aula e utilizando o roteiro de análise didática, acima apresentado).

As questões teóricas, de natureza curricular, levantadas nas análises didáticas da aulas filmadas e estudadas coletivamente pelos professores no Curso, são um exercício coletivo e lento para instrumentalizar os professores em busca de elevar o seu nível de reflexão teórica sobre a prática pedagógica, constituindo-se numa tecnologia social de formação profissional de educadores.

C) Experimentação de metodologias participativas de construção curricular, como: Temas Geradores (na perspectiva freireana), Pedagogia de Projetos e Redes Temáticas discutindo os conteúdos/conhecimentos numa perspectiva intercultural crítica, que busquem desvendar/estimular componentes curriculares que potencializem o papel da escola na preservação/fortalecimento da cultura local (indígena, caiçara e quilombola).

Assim, esses três eixos se desdobram nas etapas mais gerais da metodologia de construção curricular que são: Sensibilização; Estudo de Uma nova Visão de Área; Diagnóstico Sócio-Cultural; Diagnótico Sócio-Linguístico; Elaboração de Temas Geradores numa Rede Temática e finalmente o Planejamento de Projetos Pedagógicos integrados.

\section{O Diagnóstico Sócio-Cultural}


Esta atividade foi elaborada durante o primeiro "Tempo Comunidade" do Curso e teve como objetivo conhecer a realidade dos educandos, o contexto em que a escola está inserida, além dos dados obtidos servirem como ferramenta para próximas atividades, dentro do processo de re-elaboração do PPP do Colégio; é a primeira etapa na metodologia de construção curricular adotada. A atividade foi dividida em duas etapas: um questionário aplicado aos alunos e à comunidade e uma "FOFA" (Fortalezas, Oportunidades, Fraquezas e Ameaças) - um diagnóstico participativo da comunidade e da escola.

Estas ferramentas são uma etapa do processo de construção curricular diferenciado e já foi aplicada em outros contextos. Foi realizada com os professores do Ensino Fundamental II da aldeia, por professores das outras escolas localizadas em comunidades tradicionais Caiçaras e Quilombolas de Angra dos Reis e Parati, em que o IEAR/UFF também faz assessoria pedagógica coordenando a formação de professores.

Em sala de aula, os alunos construíram um questionário bilíngue, em português e em guarani; o questionário possuía perguntas sobre 6 eixos: dados pessoais, dados materiais, visão de futuro, trabalho, lazer e cultura.

Após a elaboração, foram divididos grupos de acordo com cada joapygua ${ }^{x i i i}$, e os alunos aplicaram o questionário com as suas famílias. Os questionários foram recolhidos, tabulados e transformados em gráficos, possibilitando uma análise e uma sistematização melhor.

\section{Quadro 1 - Exemplo de um bloco do questionário}

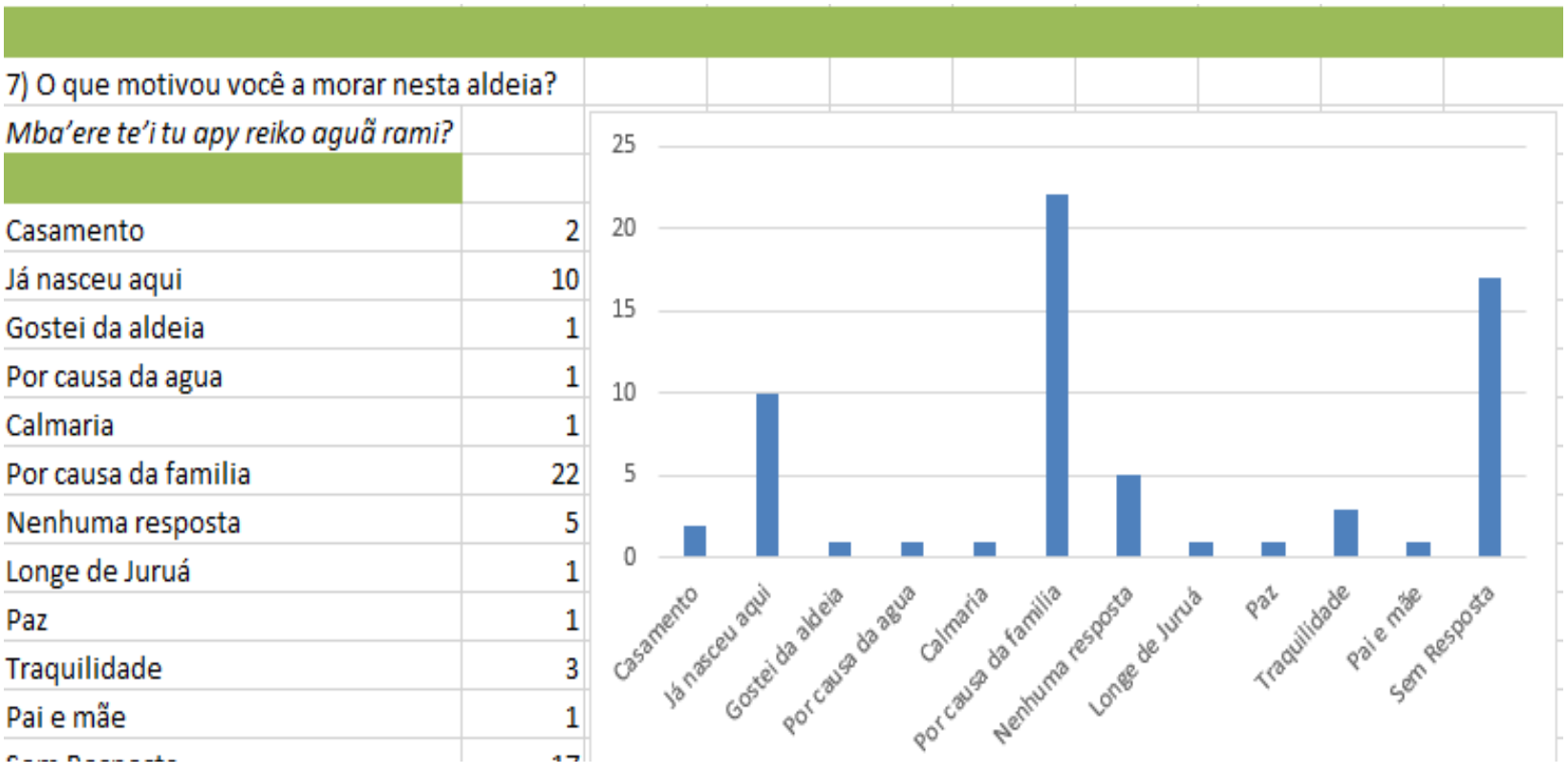




\section{Fonte: Relatório do Módulo I Disciplina Prática Reflexiva.}

Em seguida, foi realizada a "FOFA"xiv, com os alunos em sala de aula. Os alunos, também divididos em grupos, debateram as fortalezas, oportunidades, fraquezas e ameaças da comunidade, e escreveram em tarjetas palavras que representassem o debate.

\section{Quadro 2 - Exemplo de um bloco da FOFA}

\begin{tabular}{|r|r|r|}
\hline & FORTALEZAS & \\
\hline Preservação da cultura guarani & Religião & Demarcação \\
\hline Dialogo com Xeramói & Professor guarani & Professor guarani \\
\hline Língua guarani & Solidariedade & União \\
\hline Existência de um posto de saúde na & Escola dentro da comunidade & Escola dentro da aldeia \\
\hline escola & Acesso Fácil & Curso Magistério \\
\hline Projeto de sustentabilidade & Posto de saúde & Existência da ACIBRA \\
\hline
\end{tabular}

Fonte: Relatório do Módulo I Disciplina Prática Reflexiva.

Após a realização destas duas atividades, iniciou-se a sistematização dos debates, onde transformaram os dados obtidos no Diagnóstico Sócio-Cultural em um texto coletivo para compor o PPP - Projeto Político Pedagógico da escola. Abaixo, um exemplo de uma parte do texto coletivo produzido pelos alunos para integrar o PPP do Colégio Indígena. 


\section{AMEAÇAS}

A aceitação da igreja doutrinária na aldeia pode causar manipulação nos indígenas porque gera uma situação grave que é a perda da religião e do costume guarani resultando no sumiço da cultura, dos hábitos, de cantar coral e contar historias tradicionais.

As drogas são produtos de alto risco para seres humanos. Além do vicio, destroem a memória e as consequências de tudo isso provoca impacto para todas as comunidades e precisamos estar bem alertas em relação a isso.

A manipulação e uma ameaça, pois muitos candidatos entram na aldeia e prometem coisas para a comunidade em troca de favores. Hoje, na aldeia Sapukai, entram muitos juruá e a maioria só vai para manipular as pessoas da comunidade como as igrejas que levam cesta básica e roupas velhas para enganar, querendo nos converter.

O acesso livre é uma ameaça a comunidade indigena porque os juruá entram sem pedir a permissão do cacique e levam produtos para vender toda semana sem nota fiscal na aldeia.

Nós, os responsáveis pela aldeia, precisamos ter mais controle em relação a entrada de pessoas não autorizadas para garantir a segurança de todos aqueles que residem nesse lugar, pois isso e um risco muito grande que pode afetar em varias ocasiões.

Políticos sem ética só aparecem no ano das eleições, porque para serem eleitos eles precisam de votos, por isso os candidatos vão fazer campanha na comunidade onde moramos, nos prometendo coisas que muitas vezes não cumprem.

O descumprimento de demandas institucionais serve como grande ameaça para nós Guarani Mbya. Instituições como a SESAI e FUNAI entre outros, tem a obrigação de atender demandas indigenas. A FUNAI tem o dever de defender os direitos indigenas, mas nem isso eles fazem e a SESAI tem a obrigação de melhorar a saúde indígena, como trazer os medicamentos para o Posto de Saúde e também fazer os consertos dos carros que estão parados na oficina com prazos que não são cumpridos.

A falta de fiscalização nas nossas áreas tem sido prejudiciais; por causa dessa falta vem facilitando a invasão por parte de caçadores grileiros e fazendeiros. Esses nossos vizinhos já fazem captação da água de nosso território e às vezes seus animais entram, ficam e causam prejuízo em nossas plantações.

A atividade contou com a participação intensa dos alunos e da comunidade, onde puderam refletir sobre a realidade em que a aldeia está inserida hoje e sobre o papel que a escola desempenha em valorizar e potencializar a cultura, assim como sua importância para que se constituam em sujeitos críticos e autônomos.

\section{Cartografia social}

Foi desenvolvido um mapeamento socio-cultural da Aldeia Sapukai, através da cartografia social, com os alunos do curso, onde se apontou a distribuição dos moradores pelos joapygua ${ }^{x v}$, a presença das lideranças e xeramõi, o número de anciãos, adultos, jovens e 
crianças em cada joapygua, os elementos fundamentais da paisagem, os equipamentos construídos, etc. Chegou-se a um total de 325 moradores identificados nessa comunidade.

A cartografia social aplicada foi dividida em três etapas: na primeira com desenhos; na segunda transpondo os dados mapeados para o aplicativo Google Earth e na terceira incluindo no mapa as fotografias tiradas pelos próprios alunos numa Oficina de Fotografia.

Quadro III: Cartografia Social Etapa I-Desenhos

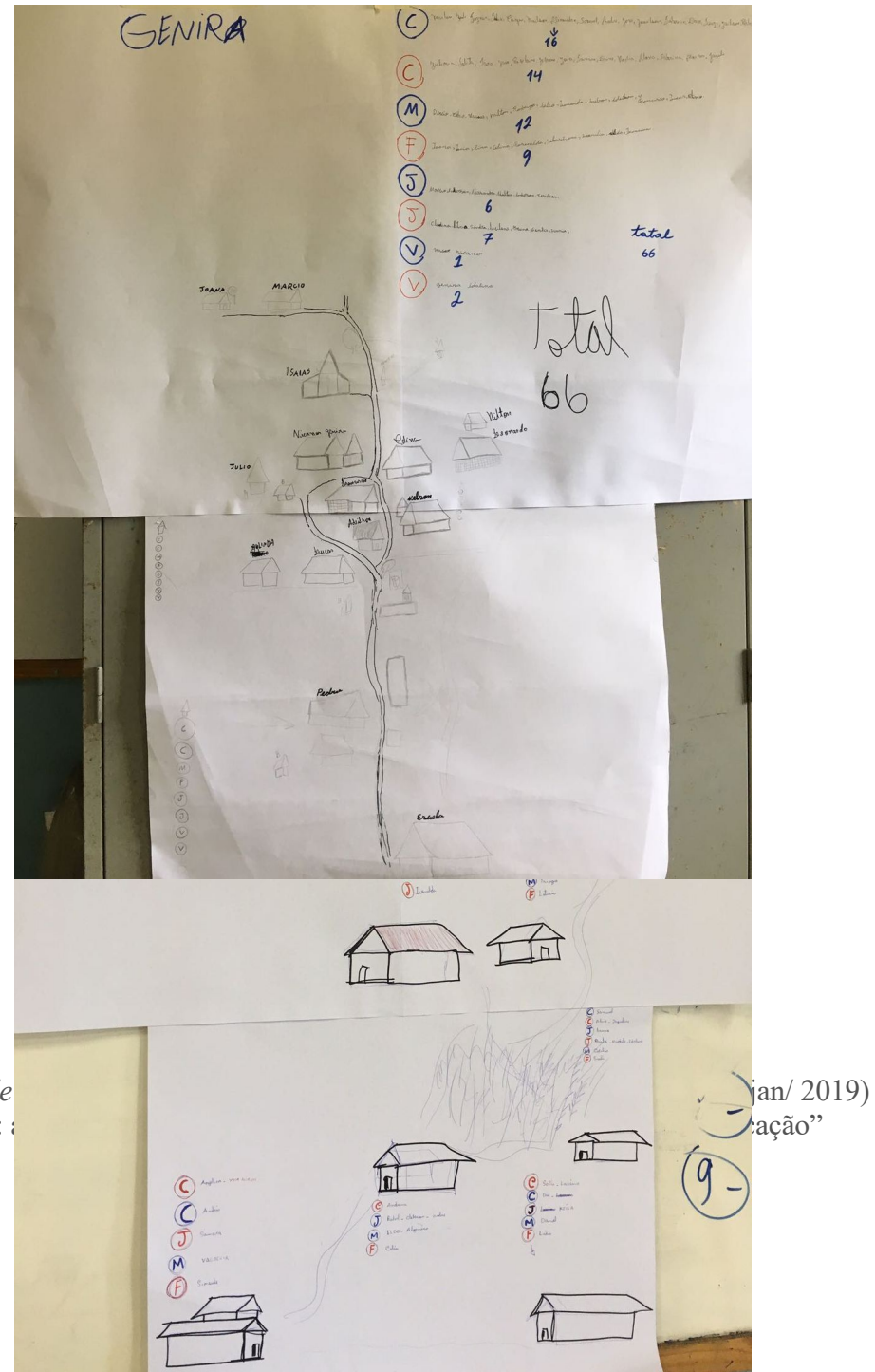


Fonte: Relatório do Módulo I Disciplina Prática Reflexiva.

Quadro III: Cartografia Social Etapa I - Desenhos

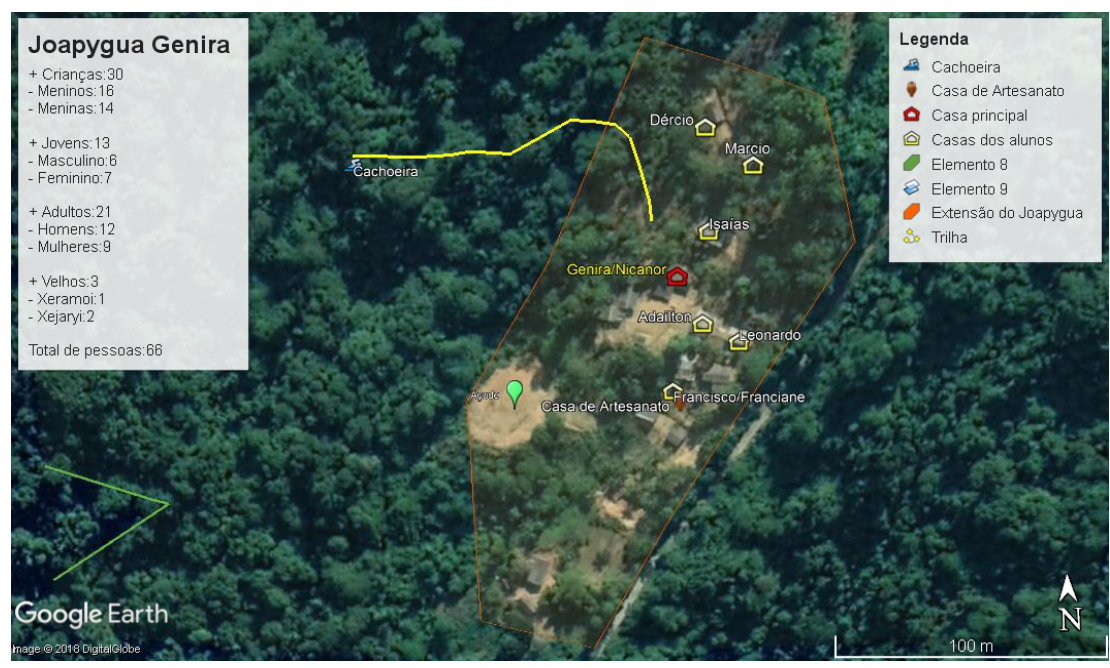

Fonte: Relatório do Módulo I Disciplina Prática Reflexiva.

Entende-se que a atividade possibilitou a discussão dos conceitos integradores de Geografia: Espaço, Território e Paisagem de forma significativa e referenciada social e culturalmente, permitindo uma reflexão crítica da gestão do território indígena, assim como de Língua Portuguesa e Guarani, pois foram produzidos inúmreos textos frutos da reflexão 
coletiva do diagnóstico, além de levantar dados fundamentais da cultura e do nhandereko ${ }^{x v i}$ das famílias dos alunos, que serão fundamentais para planejar projetos pedagógicos integrados e interdisciplinares, como se pretente na metodologia de construção curricular que permeia o curso.

Apesar de estar em seu início de implantação, temos certeza que a experiência aponta uma pista para a construção de uma formação intercultural crítica, diferenciada, decolonial e bilingue, na medida em que estrutura o Curso de Magistério dentro de uma metodologia que acompanha de forma coerente, do ponto de vista teórico-metodológico, a construção de um currículo integrado e intercultural também para o Colégio Indígena, onde os futuros professores atuarão, assim como tem sido uma experiência inovadora de Ensino, Pesquisa e Extensão para a Universidade.

\section{REFERÊNCIAS}

BRASIL. Lei No 9.394, de 20 dezembro de 1996. Lei de diretrizes e bases da educação nacional. Brasília: Ministério da Educação. 1996. Disponível em:

$<$ http://www.planalto.gov.br/ccivil_03/leis/L9394.htm>. Acesso em: 13 de dez. 2018.

BONAFÉ, Jaume Martínez. La ciudad en el curriculum y el curriculum en la ciudad. Canoas: Fórum Mundial de Educação, 2014.

CANDAU, Vera Maria F.; RUSSO, Kelly (Org.) Interculturalidade e educação na América Latina: uma construção plural, original e complexa. Revista Diálogo Educacional, vol. 10, num. 29, 2010.

CASTRO-GÓMEZ, Santiago; GROSFOGUEL, Ramón. El giro decolonial: reflexiones para una diversidad epistémica más allá del capitalismo global. Bogotá: Siglo del Hombre Editores; Universidad Central, Instituto de Estudios Sociales Contemporáneos y Pontificia Universidad Javeriana, Instituto Pensar, 2007.

COLETIVO DE APOIO À EDUCAÇÃO DIFERENCIADA do FCT - Fórum de Comunidades Tradicionais. A Educação escolar das comunidades tradicionais de Paraty. Um Balanço de 2 anos do Plano Municipal de Educação. (2015-2017). Paraty. 2018. 
FREIRE, Paulo. Pedagogia do Oprimido. Rio de Janeiro: Paz e Terra, 1987 [1970]

HERNÁNDEZ, F. Transgressão e Mudança na Educação: os Projetos de Trabalho. Porto Alegre: Artes Médicas. 1998.

, \& VENTURA, M. A Organização do Currículo por Projetos de Trabalho - o

Conhecimento é um Caleidoscópio. Artes Médicas. Porto Alegre. 1998.

MONTEIRO, Licio Caetano do R.; NOBRE, Domingos B.; OLIVEIRA, Mara Edilara B.

(Org.). Caderno pedagógico para projetos de educação escolar diferenciada e intercultural:

a produção do guia turístico local nas escolas Martim de Sá, na Praia do Sono, e Cajaíba, no Pouso da Cajaíba. Paraty: Coletivo de Apoio à Educação diferenciada / Fórum de Comunidades Tradicionais, 2017.

, Escolas do Território nas comunidades caiçaras de Paraty: um encontro entre currículo escolar, saberes tradicionais e territórios em conflito. Paraty: Projeto Licenciaturas. IEAR/UFF. 2018.

MOREIRA. Marco Antônio. Aprendizagem significativa. A teoria de David Ausubel. São Paulo: Centauro. 2006.

NOBRE, Domingos (Org.) Curso de Magistério Indígena Guarano do Estado do Rio de Janeiro. Angra dos Reis: IEAR/UFF/Colégio Indígena Estadual Guarani Karai Kuery Renda/ SEEDUC-RJ. 2017.

< Breve Histórico da Aldeia Sapukai- Angra dos Reis/RJ. 2001. Disponível em:

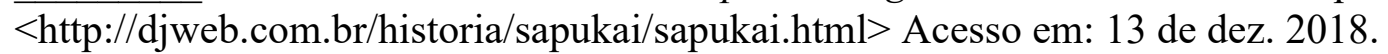

, (Org.) Relatórios do Módulo I Disciplina: Prática Reflexiva do Curso de Ensino Médio com Habilitação em Magistério Indígena. Angra dos Reis: IEAR/UFF/Colégio Estadual Indígena Guarani Karai Kuery Renda. Angra dos Reis. 2018.

2001.

, Relatórios do NEI-RJ. Rio de Janeiro: CEDAC - Centro de Ação Comunitária.

PONTUSCHKA, N. O conceito de estudo do meio transforma-se em tempos diferentes, escolas diferentes, com professores diferentes. In: VESENTINI, J. (org.). O ensino de geografia no século XXI. Campinas: Papirus, 2004.

PORTO-GONÇALVES, Carlos Walter. De saberes e de territórios: diversidade e emancipação a partir da experiência latino-americana. In: V. do C. Cruz; D. A. Oliveira. (Org.). Geografia e Giro Descolonial. Rio de Janeiro: Letra Capital, 2017.

SOUZA, Marcelo Lopes de. Os conceitos fundamentais da pesquisa socio-espacial. Rio de Janeiro: Bertrand Brasil, 2013.

Revista Interinstitucional Artes de Educar. Rio de Janeiro, V. 4 N. 3 - pag 599-622 (out/2018 - jan/ 2019) 
RIO DE JANEIRO. Decreto n. 33.033, de 22 de abr. de 2003. Cria a categoria de Escola Indígena no Âmbito da Educação Básica, no Sistema Estadual de Ensino Do Estado do Rio de Janeiro. Rio de Janeiro, abr. 2003. Disponível em:

$<$ http://www.silep.planejamento.rj.gov.br/decreto_33_033_22042003.htm> Acesso em: 13 de dez. 2018.

RIO DE JANEIRO. Resolução SEEDUC No 5227, de 06 de março de 2015. Diário Oficial do Estado do Rio de Janeiro, Poder Executivo, Rio de Janeiro, RJ, Seção 1. Disponível em: $<$ http://www.rj.gov.br/c/document_library/get_file?uuid=59c13ab3-a01c-41a1-9824cd76fb22b60e\&groupId=91317> Acesso em: 13 de dez. 2018.

TUBINO, Fidel. Del interculturalismo funcional al interculturalismo crítico. In: Diálogos: Culturas, espiritualidades y desarrollo andino -amazónico, Año 1, Nº1 2011.

\footnotetext{
i Professor Adjunto do Instituto de Educação de Angra dos Reis (IEAR)UFF. Pós-doutorando em Linguística pela UFRJ, na linha de pesquisa: Estudo das Línguas Indígenas Brasileiras.

ii Mestranda do Programa de Pós-Graduação da UNIRIO (PPGEdu).

iii Kyrĩgue Yvotyty - Jardim das Crianças.

iv Karai Kuery Renda - Lugar dos Sábios.

${ }^{v}$ Ramõi e Jaryi - Avôs e Avós.

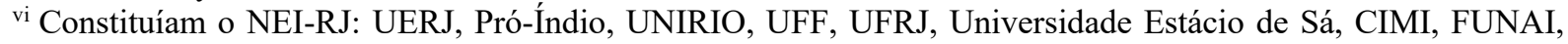
CEDAC, SME de Angra dos Reis, SME de Parati, MPF, além de professores e lideranças Guarani.

vii Significa homem barbudo, todos os não indígenas, na língua Guarani Mbya.

viii Programa de Extensão Universitária.

ix Programa Institucional de Bolsa de Iniciação Científica.

x Do qual integram: Profs. Domingos Nobre (Coordenador), Lício Monteiro, Diogo Cirqueira, Dila Carvalho, Anna Vecchia e 8 professoras do NEPEDIF - Núcleo de Estudos e Pesquisas em Educação Diferenciada do CP II - Colégio Pedro II - Unidade Humaitá, coordenado por Inês Sá.

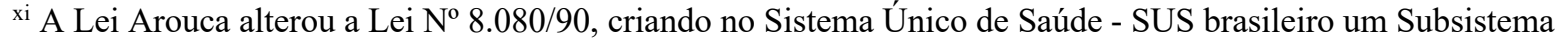
de Atenção à Saúde Indígena, organizando-o em Distritos Sanitários Especiais Indígenas - DSEI.

xii Grupo de Pesquisa (CNPQ): "Espaços Educativos e Diversidade Cultural".

xiii Palavra da Língua Guarani utilizada como referência aos agrupamentos ou grandes núcleos de família extensa.

${ }^{\text {xiv }}$ FOFA - Técnica de diagnóstico participativo popular que se constitui na discussão coletiva de: Fortalezas, Oportunidades, Fraquezas e Ameças da comunidade.

${ }^{x v}$ Joapygua - Núcleo de família extensa, base estruturante da organização social guarani mbya.

${ }^{\text {xvi }}$ Nhandereko - Nosso modo de ser.
} 